\title{
COUP IIOEIL SUR LA VIE INTIME DES CAMBARUS
}

\author{
par G. EMPIRE \\ Vice-Président de la Sociélé Centrale d'Aquiculture et de Pêche.
}

Je ne reprendrai pas la présentation de ces crustacés qui a déjà fait l'objet d'exposés de M. Marc André et de moi-même ; ceux que la question intéresse trouveront des renseignements complets dans l'ouvrage de notre collègue Marc André (Les Ecrevisses de France).

Ceci dit... abordons le sujet.

Parmi les habitants de nos eaux, l'Écrevisse est certainement l'un des plus curieux; j'ai observé longuement, en aquarium, des poissons, des larves, des insectes aquatiques : aucune de ces bestioles ne m'a causé autant d'intérêt, de curiosité, de surprise, que l'observation des Écrevisses, principalement des Cambarus.

Cela m'a permis de faire de nombreuses remarques sur leur manière de vivre; elles ne cadrent pas toujours avec ce qui se raconte sur ce sujet.

Les sexes. -.. Avec un peu d'habitude, on différencie facilement, à première vue, les mâles des femelles.

Les pinces du mâle sont longues et bien fendues; celles de la femelle sont plus courtes. L'abdomen est presque cylindrique chez la femelle; il est conique chez le mâle. Le dictionnaire nous apprend que l'Écrevisse est un décapode, c'est-à-dire munie de 10 pieds ou pattes.

Je m'insurge contre cette définition; l'Écrevisse possède 2 pinces, armes d'attaque ou de défense; 4 bras menus, terminés par 2 doigts dont elle se sert avec habileté.

Ces organes de préhension lui servent à saisir sa nourriture et à la porter à la bouche; ils paraissent doués d'un sens tactile très développé. J'ai vu, maintes fois, des Cambarus palper un ver de vase caché sous une pierre et s'en saisir au toucher. Les quatre pattes postérieures sont terminées, non par une pince, mais par un crochet, ce sont leurs jambes; elles servent à la locomotion.

Grâce à leurs nombreuses articulations, tous ces menus bras ou jambes semblent montés à rotules; et, les Écrevisses s'en servent pour maints usages. C'est ainsi qu'elles font leur toilette comme un chat, passent délicatement l'extrémité de leurs pattes dans les plissements de leur

(1) Résumé d'une Conférence faite à la Société Centrale d'Aquiculture et de l'êche, le 20 décembre 1951. 
carapace pour en dégager les particules limoneuses. Telles les grandes coquettes, elles se font le tour des yeux; se grattent aussi bien le dessous du ventre que le milieu du dos, etc. Sous ce rapport, tout rois de la Création que nous sommes, nous ne pouvons rivaliser avec elles. Leur sens olfactif est très développé.

En eau claire, j'en ai vu remonter de très loin sur la traînée sapide d'un paquet de tripes de volaille déposées au fond d'une balance.

Reproduction. - En ce qui concerne la reproduction, les observations faites sur les Cambarus ne concordent pas avec celles qui ont cours pour les Écrevisses indigènes.

Pour ces dernières, il est admis que l'accouplement se situe en Octobre ; le mâle dépose sur la face ventrale de la femelle, à la base des pattes, un sperme adhérent; la ponte débuterait quelques jours après, les œufs collés sur les filaments externes de la paroi ventrale de l'abdomen. Pour les Cambarus, la genèse de cette histoire d'amour se passe un peu différemment; il faudrait la plume d'un Fabre ou d'un Maeterlinck pour en conter les épisodes.

Dès Octobre, mâles et femelles sont en grande effervescence, les mâles circulent activement à la recherche de l'âme sœur. Quand ils se sont rencontrés, c'est généralement la femelle qui fait les avances. Elle saute, tourne, gambade, tel un jeune chien invitant un collègue à jouer. Cette danse amoureuse semble émoustiller notre loustic; ses antennes vibrent avec rapidité, il fonce sur sa partenaire, la renverse sur le dos, saisissant dans ses pinces celles de la femelle, l'immobilisant complètement.

L'accouplement commence. Le Cambarus est doué d'un tempérament volcanique et le dicton " chaud de la pince " a certainement été lancé par un observateur de Crustacés.

Le corps à corps amoureux dure jusqu'à 10 à 12 heures et même davantage, comme j'ai pu le constater. Cette période d'effervescence se prolonge, pour les mâles, jusqu'en Janvier et même bien plus tard. Qnand les femelles sont fécondées, elles se retirent dans des trous et ne circulent guère.

Dans cette espèce, ce n'est que vers la mi-Avril que l'on trouve la femelle grainée extérieurement; celle-ci prend grand soin de ses œufs.

Ployée sur la queue et sur l'extrémité des pinces elle passe de longues heures à les agiter, à les laver, pour éliminer le limon qui risquerait d'étouffer les embryons.

Quand ils sont à maturité, la mère peigne délicatement ses ovaires pour en détacher les œufs arrivés à maturité ; je n'ai pu obtenir d'éclosions.

Accouplement. - La frénésie génétique des mâles est telle que j'ai vu des sujets de sexes différents capturés soit à la ligne, soit aux balances, s'étreindre de suite dès qu'ils étaient placés dans le récipient servant au transport, et se laisser manipuler, étroitement enlacés, sans faire aucune tentative de séparation.

Le 4 Décembre 1932, ayant capturé quatre Cambarus en Marne, j'ai observé l'accouplement d'un mâle et d'une femelle qui dura de $21 \mathrm{~h}$. 30 le soir à 12 h. 15 le lendemain. Du 4 au 19 Décembre, j'ai constaté 11 saillies 
en quinze jours et observé des accouplements s'étendant depuis Octobre jusqu'en Avril.

Grainage. - Jusqu'en Mars, les femelles n'étaient pas grainées extérieurement. Le 8 Avril 1934 et le 16 Avril 1933, j'ai trouvé des femelles grainées extérieurement mais beaucoup d'autres ne l'étaient encore qu'intérieurement.

Mue. - Je n'ai pas constaté de période bien fixe pour la mue, en ayant observé depuis Mai jusqu'en Octobre et même Décembre.

Quand le Crustacé commence à muer, il donne des signes d'inactivité, la carapace se fonce, prend des nuances plus vives, les yeux deviennent vitreux, l'animal semble avoir peine à se mouvoir, il est agité de contractions de temps à autre. La mue commence par la désarticulation de la carapace du thorax, s'arrêtant à l'extrémité du museau, l'animal dégage tête et pattes puis l'abdomen. Cette opération est longue et dure plus ou moins longtemps suivant que l'animal est vigoureux ou non. Par deux fois, j'ai observé des cas de cannibalisme, celle qui muait étant attaquée par une voisine.

Les mues, en séchant, passent au rouge crevette dans un délai d'environ huit jours.

Le changement de coloration débute par l'extrémité caudale pour gagner peu à peu la partie antérieure du corps et des pinces.

Remarquer la délicatesse de ce changement de test, puisque les deux longues antennes se dépouillent également.

Pour faciliter ce changement de corset il se produit une sécrétion glaireuse qui sert de lubrifiant.

La mue est une période critique que des Crustacés affaiblis ne supportent pas.

Rusticité. - Les Cambarus sont bien plus rustiques que nos Écrevisses indigènes. En Juillet 1932, dans une boule de verre de 4 litres, l'eau avait atteint $30^{\circ}$; sur trois prisonnières deux sont mortes, la troisième a résisté. Le 3 Février 1935, j'ai retrouvé un sujet qui était resté prisonnier sous le plancher d'un bateau à moteur dans un mélange d'eau sale et d'huile de graissage. Il était là depuis le 30 Décembre 1934 ! Cette rusticité explique pourquoi ils résistent si bien dans les eaux polluées de la Basse-Seine, en_aval de Paris.

Nourriture. - Après examen du contenu stomacal de nombreux sujets, M. Marc André a surtout trouvé des détritus végétaux. En 1927, deux spécialistes, M. Lehmann et Quiel, n'ont trouvé aucune trace alimentaire animale, mais surtout des fragments de végétaux, des Diatomées et quelques Rotifères. Pour ma part, j'ai constaté qu'elles mangent n'importe quoi, mais leur régal est un bouquet de cresson; si elles attaquent un poisson mort ou blessé, elles n'ont pas l'agilité nécessaire pour courser un poisson vivant. Elles ont d'ailleurs leurs ennemis : Barbeaux, Perches, Brochets, Chevaines, Lottes leur font la chasse, non seulement à l'époque de la mue, mais aussi à tout autre moment. 